\title{
On detecting a trend in the residual circulation from observations of column $\mathrm{HCl}$
}

\author{
M. A. Olsen, A. R. Douglass, R. S. Stolarski, and M. R. Schoeberl \\ Atmospheric Chemistry and Dynamics Branch \\ NASA Goddard Space Flight Center \\ Greenbelt, MD
}

The troposphere is the part of the atmosphere where people live. The troposphere goes up to about $12 \mathrm{~km}$ above the earth over places at middle latitudes like Washington, D.C. The next layer of air up in the atmosphere is called the stratosphere. The tropopause separates the troposphere and stratosphere. Most of the ozone in the atmosphere is in the stratosphere where it protects people from the harmful rays in sunlight. Near the earth's surface, ozone is a pollutant. In general, air travels from the troposphere to the stratosphere through upward motion in the tropics. Most of the air comes back down to the troposphere at middle latitudes. The so-called "stratospheric residual circulation" moves the air in the stratosphere from the tropics to the middle latitudes. In this way, the amount of air that moves out of the stratosphere into the troposphere at middle latitudes depends on the strength of the residual circulation. This overturning of the atmosphere is important as it brings chemicals produced by the activities of people into the stratosphere. Most notable are chlorofluorocarbons (CFCs) that destroy stratospheric ozone. The transport of air out of the stratosphere removes ozone-destroying chemicals, but also brings ozone into the troposphere.

Previous studies using atmospheric models have shown that the residual circulation and the amount of air that crosses the tropopause change because of increased chemicals produced by people in the atmosphere. The strength of the residual circulation will contribute to how much of a chemical can be found in the stratosphere at any time. Increasing the speed of transport from the stratosphere to the troposphere would also increase how fast ozone-destroying chemicals are removed from the stratosphere. Thus, knowing the strength of the residual circulation is needed to predict when the amount of ozone in the stratosphere will return to the greater levels that existed in the past.

This work shows a method of detecting a change in the residual circulation from observations of hydrogen chloride $(\mathrm{HCl}) . \mathrm{HCl}$ in the atmosphere is primarily produced by chemical reactions in the stratosphere. For several years, instruments on the ground have made measurements of how much $\mathrm{HCl}$ exists in the atmosphere directly above them. This type of measurement is called the "column $\mathrm{HCl}$ ". The middle latitude column $\mathrm{HCl}$ tends to be greatest in the late winter and least in the late summer. The amount that the column $\mathrm{HCl}$ changes within a year tells us how strong the residual circulation is. Many measurements are needed each year to find out how much the column $\mathrm{HCl}$ changes. So far, not enough years have enough measurements to show if the residual circulation is changing. This work shows that many instruments working together for a few more years could determine if the residual circulation is changing. 


\title{
On detecting a trend in the residual circulation from observations of column HCI
}

\author{
Mark A. Olsen ${ }^{1}$ \\ Anne R. Douglass ${ }^{2}$ \\ Richard S. Stolarski \\ Mark R. Schoeberl ${ }^{2}$ \\ ${ }^{1}$ Goddard Earth Sciences and Technology Center, University of Maryland, Baltimore \\ County, Baltimore, Maryland, USA \\ ${ }^{2}$ NASA Goddard Space Flight Center, Greenbelt, Maryland, USA
}

\begin{abstract}
Ground-based measurements show that the $\mathrm{HCl}$ column at middle latitudes varies seasonally with a late spring maximum and a minimum in late summer. HALOE measurements of $\mathrm{HCl}$ profiles show that this seasonal cycle in the column is controlled by the seasonal variations of the mass and composition of the lowermost stratosphere. The seasonal maxima are produced by wintertime downward transport of stratospheric air. We hypothesize that the amplitude of the seasonal cycle is quantitatively related to the strength of the stratospheric residual circulation and stratosphere-troposphere exchange (STE). We investigate this relationship using a multi-decadal simulation from the GSFC Chemistry and Transport Model driven by output from a general circulation model in which an STE trend exists. We also examine the ground-based record of $\mathrm{HCl}$ measurements at Jungfraujoch for evidence of a trend in the $\mathrm{HCl}$ seasonal amplitude that would be a signature of a long-term change in the stratospheric circulation.
\end{abstract}




\section{Introduction}

General circulation models have been shown to exhibit a change in the residual circulation as a result of climate-induced change in atmospheric composition [e.g., Rind et al., 1998; Sigmond et al., 2004; Eichelberger and Hartmann, 2005]. If such a trend is real, it would contribute to observed trends in stratospheric trace gases including ozone. Butchart and Scaife [2001] have demonstrated that increasing the rate of mass exchange between the stratosphere and troposphere accelerates the removal of chlorofluorocarbons (CFCs) from the stratosphere and would alter ozone recovery. The present study introduces a novel method of detecting a change in the residual circulation.

Both the change in the mass of the lowermost stratosphere and the change in the $\mathrm{HCl}$ mixing ratio dominate the seasonal variation observed in the column. The mass of the extratropical lowermost stratosphere is a maximum in the winter when the tropopause is lowest and a minimum during summer when the tropopause is highest [Schoeberl, 2004]. The composition of the middle latitude lowermost stratosphere is dominated by downward transport of stratospheric air from the region above $380 \mathrm{~K}$ in the winter. In the summer, sub-tropical tropospheric air is quasi-isentropically transported into the middle latitude lowermost stratosphere (the region between $380 \mathrm{~K}$ and the tropopause), resulting in a composition that is more tropospheric in character [e.g., Ray et al., 1999; Pan et al., 2004]. Middle latitude ground based measurements of the $\mathrm{HCl}$ column vary from a maximum in late winter to a minimum in late summer. The stratospheric column above $100 \mathrm{hPa}$ from profiles measured by the Halogen Occultation Experiment (HALOE) on the Upper Atmosphere Research Satellite are nearly constant throughout the year, thus the seasonal variability of the lowermost stratospheric mass and $\mathrm{HCl}$ are manifest in the column measurements.

Based on the discussion above it seems likely that the amplitude of the seasonal cycle of mid-latitude column $\mathrm{HCl}$ can be used as a marker of the residual circulation. The annual maximum in the $\mathrm{HCl}$ column is sensitive to a change in the stratospheric residual circulation through the downward flux of $\mathrm{HCl}$ into the lowermost stratosphere. A stronger (weaker) residual circulation will produce a larger (smaller) late winter maximum in the $\mathrm{HCl}$ column. The seasonal minimum of the column will remain relatively unchanged since it is caused by the flux of low $\mathrm{HCl}$ tropospheric air into the lowermost stratosphere. Thus, greater seasonal amplitude of the $\mathrm{HCl}$ column will exist under the condition of a more vigorous residual circulation. Here we use a multi-decadal simulation with a trend in the mass stratosphere-troposphere exchange (STE) to quantify the relationship between STE and the mid-latitude column $\mathrm{HCl}$ annual amplitude. We also examine the existing ground-based observation record for such a signature of an increasing residual circulation.

\section{Simulation and Data}

(a) Chemistry and transport model and simulation 
We performed a simulation for 1973-2023 using the GSFC Chemistry and Transport Model (CTM) [Stolarski et al., 2006]. Boundary conditions of source gases, including observed and projected CFCs and other sources of chlorine, are taken from scenario A2 [WMO, 2003]; Stolarski et al. [2006] provide details of the simulation. Meteorological fields from the GEOS-4 general circulation model (GCM) [Bloom et al., 2005] are used to drive the CTM. The GCM uses Hadley Centre monthly mean sea surface temperatures for the years 1949 to 1998. Douglass et al. [2003] use comparisons of observations of long-lived tracers with fields from a CTM simulation driven by an earlier version of GEOS-4 to show that the large-scale stratospheric transport of the GCM is realistic. Schoeberl et al. [2003] show that the age-of-air and residual circulation produced by these GCM fields are reasonable. Olsen et al. [2004] show that the flux of mass and ozone from the stratosphere to the troposphere compares well with estimates based on observations.

\section{(b) HALOE and FTIR observations of $\mathrm{HCl}$}

The Halogen Occultation Experiment (HALOE) on the Upper Atmosphere Research Satellite (UARS) measured the composition of the stratosphere and mesosphere by solar occultation limb sounding from 1991-2005 [Russell et al., 1993]. Thirty vertical profiles of seven chemical species, including $\mathrm{HCl}$, were made daily. In 1997, power sharing necessitated by battery problems reduced HALOE coverage.

Regular ground based measurements of column $\mathrm{HCl}$ have been made by Fourier Transform Infrared (FTIR) spectrometers of the Network for the Detection of Stratospheric Change (NDSC). The longest on-going record exists at Jungfraujoch extending back to 1989. The random and systematic errors of each measurement are $\pm 3 \%$ and $\pm 5 \%$, respectively [Rinsland et al., 2003].

\section{Results}

The simulated stratospheric $\mathrm{HCl}$ reproduces the main features of $\mathrm{HALOE}$ observations (Figure 1). Similar to the observations, the seasonal cycle in the mid- to upperstratosphere is relatively flat and almost all of the variability in the column of $\mathrm{HCl}$ comes from the lowermost stratosphere. The simulation is biased high with respect to the observations but is within the calibration error estimates of HALOE [Russell et al., 1996]. Any mean bias of the simulated $\mathrm{HCl}$ compared with observations is irrelevant to this study and is removed from the comparison in Figure 1. The key point of this comparison is that the seasonal cycle in the lowermost stratosphere is reproduced well by the simulation and the seasonal amplitudes are similar.

Figure 2 compares the monthly mean Fourier Transform Infrared Spectrometer (FTIR) $\mathrm{HCl}$ column measured at Jungfraujoch $\left(46.55^{\circ} \mathrm{N}\right)$ with the simulated column at $50^{\circ} \mathrm{N}$. We choose this comparison with a latitudinal offset (one model grid point) so that the mean magnitudes are similar. This offset does not alter our conclusions presented in this work. Overall, the interannual trend and seasonal amplitude of the simulated $\mathrm{HCl}$ column compare well with the available FTIR data. The interannual trend reflects the 
specified boundary conditions of chlorine species. The CTM simulation includes the aerosol loading of two major volcanic eruptions, El Chichon in 1982 and Pinatubo in 1991. The eruption of Pinatubo in 1991 results in a substantial decrease of the seasonal amplitude of the zonal mean simulated $\mathrm{HCl}$ column. In comparison, significantly low values of column $\mathrm{HCl}$ are observed over Jungfraujoch during winter 1991/1992.

We have calculated the annual extratropical STE of mass in the GCM simulation using the mass balance diagnostic of Olsen et al. [2004]. The STE exhibits an increasing trend of 3\% per decade in the Northern Hemisphere (Figure 3) and 2\% per decade in the Southern Hemisphere (not shown). This trend in the mass STE and the forcing will be discussed in a future work. The focus of the present study is the relationship of the seasonal amplitude of the $\mathrm{HCl}$ column to STE.

We determine the zonal mean column $\mathrm{HCl}$ seasonal cycle amplitude by fitting a linear function of an annual sine and cosine. The amplitude is divided by the annual mean and expressed as a percent to remove the trend of atmospheric chlorine. This normalization also removes the impact of the volcanic aerosol loading.

The time series of the zonal mean column $\mathrm{HCl}$ seasonal amplitude at $50^{\circ} \mathrm{N}$ from the simulation is shown in Figure 4a. Over the entire time series, the $\mathrm{HCl}$ amplitude increases at $9.7 \%$ per decade. We are currently preparing a paper that shows that a change in the STE is coupled with a change in the stratospheric residual circulation. Figure $4 \mathrm{~b}$ shows that the simulated annual $\mathrm{HCl}$ amplitude and STE are significantly correlated at greater than $99 \%$ confidence, consistent with the trend in the residual circulation as the cause of the increasing trend in the $\mathrm{HCl}$ seasonal amplitude. The residual circulation driven flux of $\mathrm{HCl}$ from the region above $380 \mathrm{~K}$ to the lowermost stratosphere increases, and this results in greater column $\mathrm{HCl}$ seasonal amplitudes.

To separate the change in residual circulation from the changes in chlorine loading, a second simulation for 1979-2001 was run with source gas boundary conditions fixed to 1979 levels. All other boundary conditions and driving meteorological fields were identical to the longer simulation. The column $\mathrm{HCl}$ seasonal amplitude increases at a rate of about $13 \%$ per decade and is also significantly correlated with STE in the fixed chlorine simulation (not shown). Over the same time period, the varying chlorine simulation exhibits a $20 \%$ per decade trend. Thus, the strength of the residual circulation is a primary factor in determining the amplitude of the column seasonal cycle. However, the trend in atmospheric chlorine still contributes to the $\mathrm{HCl}$ column amplitude trend with our normalization by the annual mean. It remains advantageous to use this normalization instead of normalizing by atmospheric chlorine since aerosol influences are eliminated and it can be easily applied to ground-based data records. Atmospheric chlorine is projected to continue to slowly decrease at present day rates over the next few decades, so the significant correlation of the $\mathrm{HCl}$ amplitude and STE will persist.

The $\mathrm{HCl}$ seasonal amplitude has considerable inter-annual variability. We can estimate the number of years of observations that are needed to isolate a trend in the residual circulation given the same trend and standard deviation of the $\mathrm{HCl}$ amplitude as found in 
the simulation. Our results from the time series of the $\mathrm{HCl}$ amplitude at $50^{\circ} \mathrm{N}$ (Fig. 4a) indicate that 11 and 19 years are needed to isolate the signal with $95 \%$ and $99 \%$ confidence, respectively. If the actual trend of the amplitude is less or if the variance is greater, then the number of years needed will increase, and vice versa. The results using time series at different latitudes within $38^{\circ} \mathrm{N}$ to $50^{\circ} \mathrm{N}$ do not vary greatly. At these latitudes the calculated number of years needed range from 10 to 13 years at the $95 \%$ confidence level.

Figure 5 shows the seasonal amplitudes calculated from the FTIR measurements at Jungfraujoch. We use a Monte Carlo bootstrap method following Hood et al. [1993] to estimate the error bars for the fit of the annual sine and cosine. There are many significant gaps in the early years of the data record as can be seen in Figure 2. Fewer than seventy days have measurements in each of the years 1989-1994 and many months lack any measurements. These years are significantly under-sampled, resulting in very large estimated errors in the seasonal amplitude. Beginning in 1997, at least 100 measurements per year are recorded and all months are represented. A positive trend exists after the mid 1990's, but it is not significantly different from zero given the variance and length of the record. Thus, no evidence of an increasing residual circulation can be determined from the present data.

In the simulation, we used zonal mean $\mathrm{HCl}$ columns at a single latitude to compute the seasonal amplitude. The variability of the column $\mathrm{HCl}$ is much greater at a single location than the zonal mean. However, the number of sites of ground-based measurements of column $\mathrm{HCl}$ from the NDSC is few. We have found that the mean measurement from several middle latitude sites reduces the single station geographical and meteorological variability. We have simulated NDSC measurements by sampling the model at grid points nearest to Northern Hemisphere middle latitude NDSC sites that have any multi-year record of FTIR measurements. The variability of the average of five locations between $38^{\circ}$ and $47^{\circ} \mathrm{N}$ (Jungfraujoch at $8^{\circ} \mathrm{E}$, Zugspitze at $11^{\circ} \mathrm{E}$, Moshiri at $142^{\circ} \mathrm{E}$, Rikubetsu at $144^{\circ} \mathrm{E}$, and Mt. Barcroft at $118^{\circ} \mathrm{W}$ ) is similar to the zonal mean. Using the mean of the values sampled at these five sites we find that 11 years are needed to detect a signal at $95 \%$ confidence, the same length of time estimated for the zonal mean. This suggests that coordination of simultaneous mid-latitude NDSC FTIR measurements to reduce longitudinal variability could identify a trend in a reasonable time frame.

\section{Discussion and Conclusions}

Of the trace gases we investigated, ozone, methane and CFC's, $\mathrm{HCl}$ is most sensitive to the residual circulation and STE since it has a strong gradient in the lowermost stratosphere and the seasonal cycle above $380 \mathrm{~K}$ is flat. The seasonal cycle of ozone in the lowermost stratosphere is a convolution of transport driven changes and the seasonal variation in ozone above $380 \mathrm{~K}$ [e.g., Olsen et al., 2004]. The seasonal cycle of other long-lived gases such as methane and fluorocarbons are not as sensitive to the residual circulation since their vertical gradient in the lowermost stratosphere is relatively small. 
In summary, we have identified a method of detecting a change in the residual circulation from observations of $\mathrm{HCl}$. The seasonal amplitude of the middle latitude $\mathrm{HCl}$ column provides a marker of the magnitude of the residual circulation once the interannual trend of atmospheric chlorine is removed. Currently, a well-sampled record of ground-based observations is not long enough to confidently isolate a signal of increased circulation. Our results indicate that such a signal could be detected in a reasonable time with coordination by mid-latitude NDSC sites.

\section{Acknowledgements}

The Jungfraujoch FTIR data used in this publication was obtained as part of the Network for the Detection of Stratospheric Change (NDSC) and is publicly available (see http://www.ndsc.ncep.noaa.gov). This work was supported by NASA's EOS IDS and ACMAP programs.

\section{References}

Bloom, S., A. da Silva, D. Dee, M. Bosilovich, J.-D. Chern, S. Pawson, S. Schubert, M. Sienkiewicz, I. Stajner, W.-W. Tan, M.-L. Wu (2005), Documentation and Validation of the Goddard Earth Observing System (GEOS) Data Assimilation System - Version 4, Technical Report Series on Global Modeling and Data Assimilation 104606, 26.

Butchart, N., and A. A. Scaife (2001), Removal of chlorofluorocarbons by increased mass exchange between the stratosphere and troposphere in a changing climate, Nature, 410, 799-802.

Douglass, A. R., M. R. Schoeberl, R. B. Rood, and S. Pawson, (2003) Evaluation of transport in the lower tropical stratosphere in a global chemistry and transport model, $J$. Geophys. Res., 108(D9), 4259, doi:10.1029/2002JD002696.

Eichelberger, S. J., and D. L. Hartmann (2005), Changes in the strength of the Brewer Dobson circulation in a simple AGCM, Geophys. Res. Lett., 32, L15807, doi:10.1029/2005GL022924.

Hood, L. L., R. D. McPeters, J. P. McCormack, L. E. Flynn, S. M. Hollandsworth, and J. F. Gleason (1993), Altitude dependence of stratospheric ozone trends based on Nimbus 7 SBUV data, Geophys. Res. Lett., 20(23), 2667-2670.

Olsen, M. A., M. R. Schoeberl, and A. R. Douglass (2004), Stratosphere-troposphere exchange of mass and ozone, J. Geophys. Res., 109, D24114, doi:10.1029/2004JD005186. 
Pan, L. L., W. J. Randel, B. L. Gary, M. J. Mahoney, and E. J. Hintsa (2004), Definitions and sharpness of the extratropical tropopause: A trace gas perspective, J. Geophys. Res., 109, D23103, doi:10.1029/2004JD004982.

Ray, E. A., F. L. Moore, J. W. Elkins, G. S. Dutton, D. W. Fahey, H. Vomel, S. J. Oltmans, and K. H. Rosenlof (1999), Transport into the Northern Hemisphere lowermost stratosphere revealed by in situ tracer measurements, J. Geophys. Res., 104(D21), 2656526580.

Rind, D., D. Shindell, P. Lonergan, and N. K. Balachandran (1998), Climate change and the middle atmosphere. Part III: The double $\mathrm{CO} 2$ climate revisited, J. Clim., 11, 876-894.

Rinsland, C. P., et al. (2003), Long-term trends of inorganic chlorine from ground-based infrared solar spectra: Past increases and evidence for stabilization, J. Geophys. Res., 108(D8), 4252, doi:10.1029/2002JD003001.

Russell, J. M., L. L. Gordley, J. H. Park, S. R. Drayson, W. D. Hesketh, R. J. Cicerone, A. F. Tuck, J. E. Frederick, J. E. Harries, and P. J. Crutzen (1993), The Halogen Occultation Experiment, J. Geophys. Res., 98(D6), 10777-10797.

Russell, J. M., L. E. Deaver, M. Z. Luo, J. H. Park, L. L. Gordley, A. F. Tuck, G. C. Toon, M. R. Gunson, W. A. Traub, D. G. Johnson, K. W. Jucks, D. G. Murcray, R. Zander, I. G. Nolt, and C. R. Webster (1996), Validation of hydrogen chloride measurements made by the halogen occultation experiment from the UARS platform, $J$. Geophys. Res., 101(D6), 10151-10162.

Schoeberl, M. R., A. R. Douglass, Z. Zhu, and S. Pawson, (2003), A comparison of the lower stratospheric age spectra derived from a general circulation model and two data assimilation systems, J. Geophys. Res., 108(D3), 4113, doi:10.1029/2002JD002652.

Schoeberl, M. R., (2004) Extratropical stratosphere-troposphere mass exchange, $J$. Geophys. Res., 109, D13303, doi:10.1029/2004JD004525.

Sigmond, M., P. C. Siegmund, E. Manzini, and H. Kelder (2004), A simulation of the separate effects of middle-atmosphere and tropospheric $\mathrm{CO} 2$ doubling, J. Clim., 17, 2352-2367.

Stolarski, R. S., A. R. Douglass, S. Steenrod, S. Pawson (2006), Trends in stratospheric ozone: Lessons learned from a 3D chemical transport model, J. Atmos. Sci., (in press).

WMO (2003), Scientific Assessment of Ozone Depletion: 2002, World Meteorlogical Organization Global Ozone Research and Monitoring Project Report No. 47, Geneva, Switzerland. 

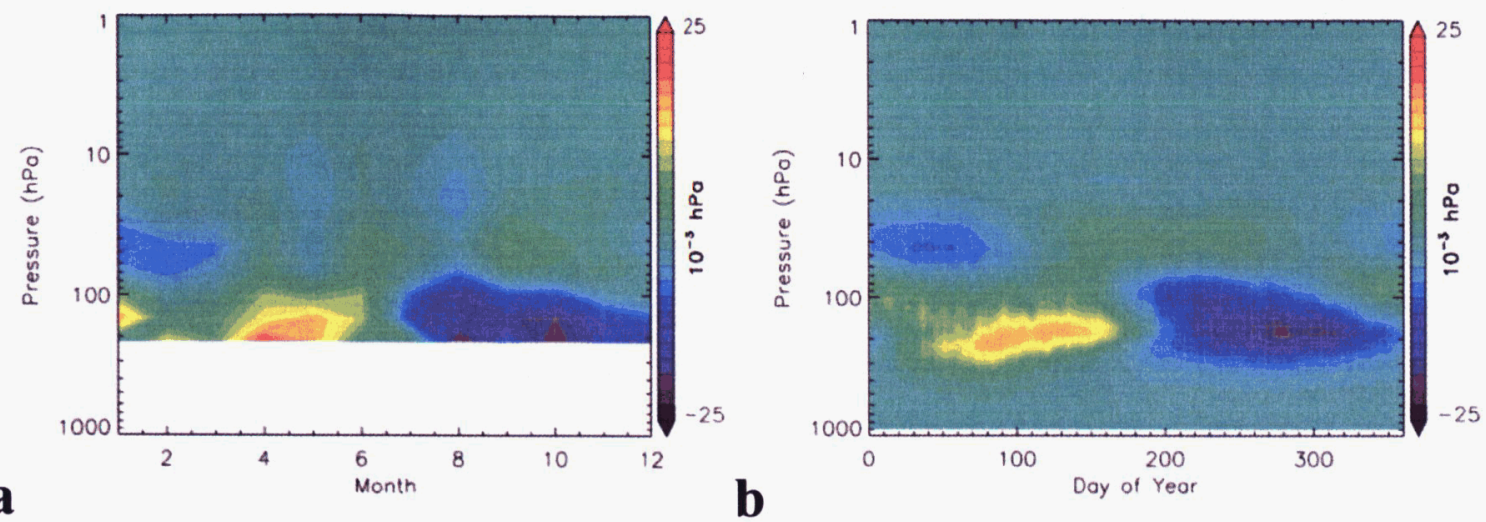

Figure 1. Seasonal cycle of partial pressure of $\mathrm{HCl}$ from (a) $\mathrm{HALOE}$ at $45^{\circ}-55^{\circ} \mathrm{N}$ and (b) CTM at $46^{\circ}-54^{\circ} \mathrm{N}$. The annual mean at each pressure surface has been removed to emphasize the seasonal cycle.

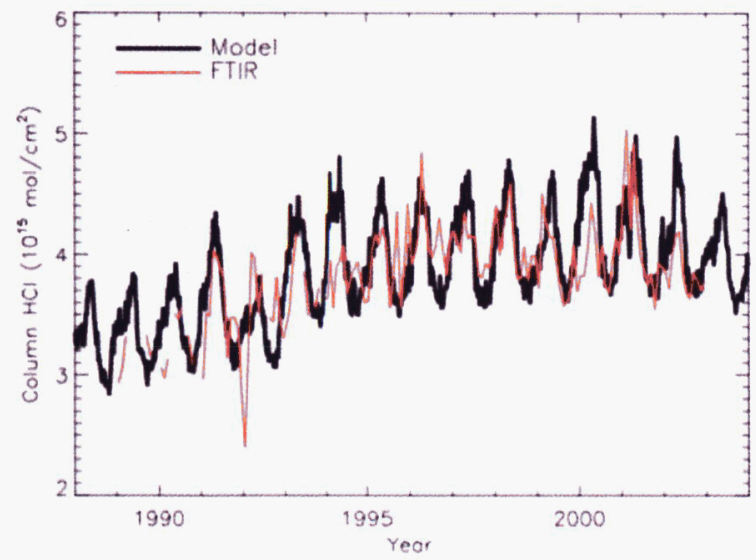

Figure 2. Time series of $\mathrm{HCl}$ column. Bold line is the model zonal mean at $50^{\circ} \mathrm{N}$. Thin red line is the monthly mean FTIR data from Jungfraujoch $\left(46.55^{\circ} \mathrm{N}\right)$. 


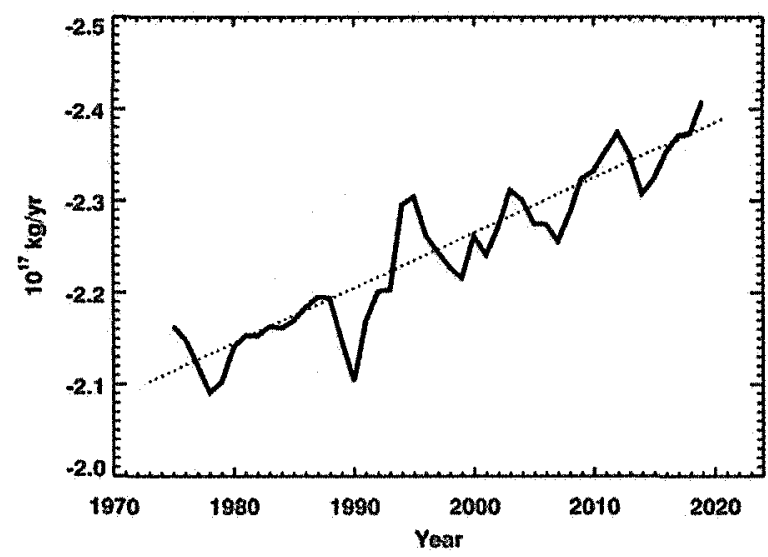

Figure 3. Annual extratropical STE for the Northern Hemisphere from a fifty-year integration of the GEOS-4 GCM. Negative values indicate net transport from the stratosphere to the troposphere. Values are smoothed using a five-year running mean.

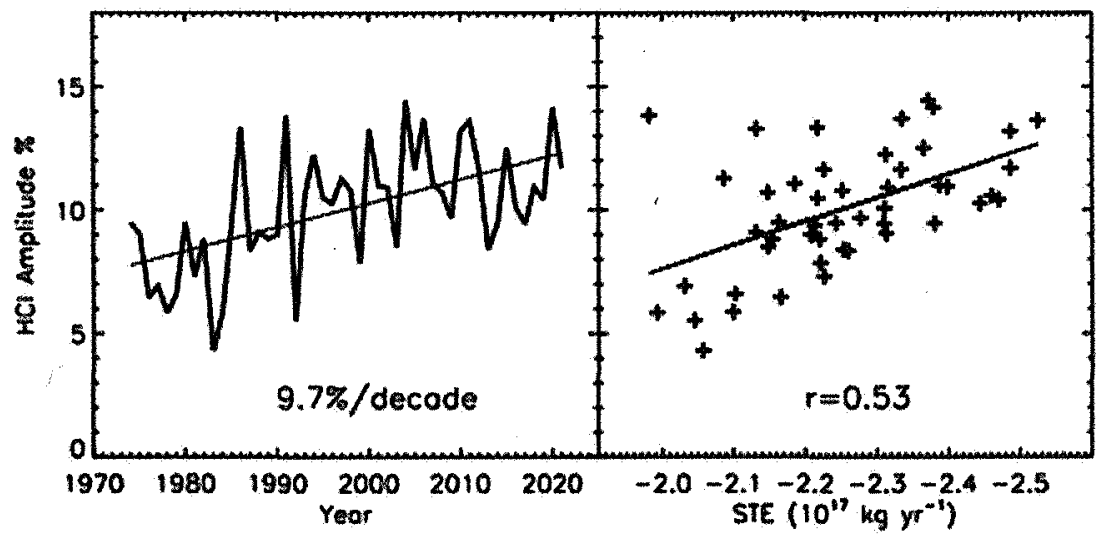

Figure 4. (a) Time series of zonal mean $\mathrm{HCl}$ seasonal amplitude from $\mathrm{CTM}$ at $50^{\circ} \mathrm{N}$. (b) Correlation of seasonal amplitude with annual extratropical STE. 


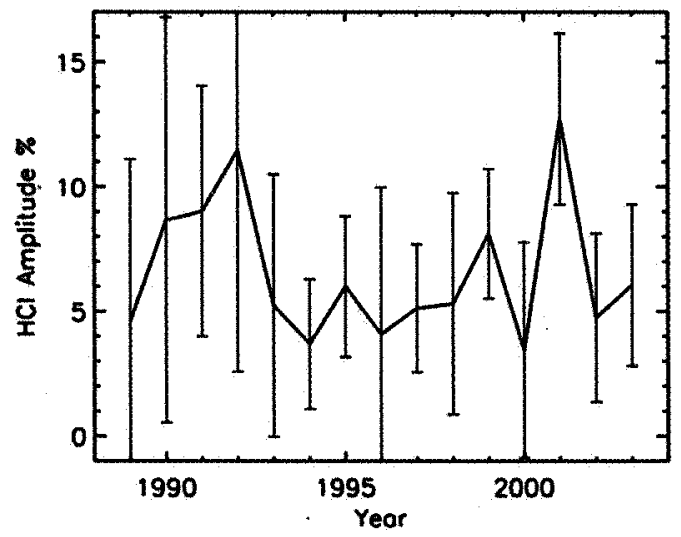

Figure 5. Time series of the seasonal amplitude of column $\mathrm{HCl}$ measured by the FTIR at Jungfraujoch. 